Journal of Animal and Veterinary Advances 10 (10): 1355-1363, 2011

ISSN: $1680-5593$

(C) Medwell Journals, 2011

\title{
Pathogenicity of Salmonella enteritidis Phage Type 1 Isolate of Malaysia in 21 Day Old Specific-Pathogen Free Chickens
}

\author{
S. Ahmad, M. Hair-Bejo, Z. Zunita and S. Khairani-Bejo \\ Faculty of Veterinary Medicine, Universiti Putra Malaysia, \\ 43400 UPM Serdang, Selangor, Malaysia
}

\begin{abstract}
Salmonella enteritidis (SE) has always been related to subclinical infection in the chickens infected after 2 weeks of hatching. However, few pathogenic phage types were proven for their ability to manifest systemic infection and cause the organism to be shed into the surrounding environment. It was the objective of the study to determine the pathogenicity of SE Phage Type (PT) 1 in Specific-Pathogen-Free (SPF) chickens. About 93, 21 day old SPF chickens where divided into 3 groups namely the Control, SE and Mortality groups. The chickens were raised separately in caging system and given free access to antibiotic-free ration and water. The SE and Mortality groups were inoculated orally $(1.0 \mathrm{~mL})$ with SE PT $1\left(1 \times 10^{8} \mathrm{cfu} \mathrm{mL} \mathrm{mL}^{-1}\right)$. The chickens in the $\mathrm{SE}$ and Control groups were sacrificed at various intervals throughout the trial. Samples were collected for bacterial isolation and histological examination. The mortality percentage of the chickens in the Mortality group was recorded. The study showed that no mortality was recorded throughout the trial in the mortality as well as the SE group. Body weight was lower in the SE group when compared to the Control group throughout the trial except at days 2, 3 and 5 post inoculation (pi) reaching its peak at day 14 pi when the SE group body weight was $26 \%$ lower than the controls. Clinical signs observed in the SE and Mortality group were represented by diarrhoea, inappetance, ruffled feather and stunted chickens while no abnormal clinical signs where recorded in the Control group. Grossly mild airsacculitis, mild peritonitis and hepatic congestion where recorded in the SE group at day 2 pi until day 5 pi while no gross lesions where recorded in the Control group. SE was first isolated in the caecum $(66 \%)$ at $12 \mathrm{~h}$ pi. At day 1 pi SE was isolated from the caecum and spleen (33\%) whilst at day $2, \mathrm{SE}$ was isolated from the caecum $(100 \%)$ and caecal tonsil $(66 \%)$. No SE was isolated from the cloacal swabs throughout the trial. The villi height was generally lower in the SE group when compared to the Controls, however it was significantly lower $(\mathrm{p}<0.05)$ in the duodenum at $12 \mathrm{~h}$, days $1,3,5,10,14$ and 21 pi; in the jejunum at $6 \mathrm{~h}$, days 2,14 and 21 pi while in the ileum at days 1,3 and 5 pi. The crypts depth measurement was fluctuating however it ended up by being higher in the SE group, nevertheless it was significantly lower $(\mathrm{p}<0.05)$ in the SE group when compared to the Control group in the duodenum at $6 \mathrm{~h}$ and day 14 pi in the jejunum at day $10 \mathrm{pi}$; in the ileum at $12 \mathrm{~h}$ pi. Histopathological changes recorded included hepatitis, congestion and focal areas of necrosis; splenitis, congestion and oedema in the adenoid sheathed arteries; congestion and areas of necrosis in the lymphoi follicles of the bursa of Fabricius; enteritis, congestion and sloughing of necrotic enterocytes in the intestinal villi with presence of bacterial clusters in the villi surface and intestinal lumen. SE rods present in the caecal tonsils were seen to be engulfed by macrophages at days 1 and 2 pi, necrosis of the enterocytes on the villi surface and infiltration of the bacteria was recorded at day 2 pi while at days 5 pi the bacteria multiplication were seen and often located upon the M-like $\mathrm{M}$ cells however, no actual engulfment was recorded.
\end{abstract}

Key words: Salmonella enteritidis, phage type 1, pathogenicity, adult SPF chickens, bacteria, Malaysia

\section{INTRODUCTION}

Paratyphoid infection has long been known as a major cause for food poisoning outbreaks worldwide by consumption of contaminated products (Saif, 2003). In the last decade Salmonella enteritidis (SE) outbreaks has elevated in its incidence rate to become the major source for food poisoning cases caused by paratyphoid Salmonella infection around the world (Le Bacq et al., 1994). Chickens are more susceptible to the SE infection at younger ages due to the lack of normal microflora and susceptibility to infection decrease dramatically after

Corresponding Author: M. Hair-Bejo, Faculty of Veterinary Medicine, Universiti Putra Malaysia, 43400 UPM Serdang, Selangor, Malaysia 
2 weeks of hatching (Desmidt et al., 1997). Adult chickens tend to act as subclinical carrier to the paratyphoid infection (Kinde et al., 2000). SE has many Phage Types (PT's) that varied in their pathogenicity and prevalence around the globe. SEPT 4 has been the major isolate in poultry and human SE infection outbreaks worldwide (Kinde et al., 2000). Other PT's such as SEPT 6, 8 and 13a have prevailed over the years in different regions (Gast and Beard, 1990; Barrow and Lovell, 1991; Kinde et al., 2000). However, their isolation rates remained lower than that of SE PT 4. SE PT 8 and 13a are the major isolates in the United States and Canada while PT4 was predominantly isolated in the United Kingdom. There has been an increased in the isolation percentage of SE PT 1 in Europe and Asia and other countries (Sakai and Chalermchaikit, 1996). A few studies indicated the ability of pathogenic SEPT's to induce a clinical infection and reduce body weight in the infected chickens and persist in the infected birds for long periods (Davies et al., 1997). The infection usually exaggerates in the immune compromised or stressed chicks by mixed infection or bad management (Soliman et al., 2009). The contamination of the adult birds will certainly form a threat for the human consumers due to contamination of poultry and their products by the pathogens. It was the objective of the study to determine the pathogenicity of SEPT 1 in 21 day old Specific-Pathogen-Free (SPF) chickens.

\section{MATERIALS AND METHODS}

Bacterial isolates: Samples of liver from commercial broiler farm in Melaka, Malaysia was collected and identified as SE using a method of Van Der Zee (1994). Briefly, the samples were collected in RappaportVassilidase (RV) broth at $37^{\circ} \mathrm{C}$ for $24 \mathrm{~h}$, cultured on Xylose Lysin Deoxycholate (XLD) agar and Brilliant Green (BG) agar at $37^{\circ} \mathrm{C}$ for $24 \mathrm{~h}$. Positive cultures where then cultured on Triple Sugar Iron (TSI) and Urease biochemical test. Positive cultures from the biochemical test where then identified serologically by Salmonella poly-O antisera using the Slide Agglutination Test (SAT).

Phage typing: Positive SE colonies where characterised by phage typing at the Laboratory of Enteric Pathogens Center for Infections Institute, 61 Collindale Avenue, London, United Kingdom by the method described by Ward et al. (1987). Briefly, a loopful of frozen nutrient broth was cultured on nutrient agar for $24 \mathrm{~h}$ at $37^{\circ} \mathrm{C}$. The positive colonies were transferred to $\mathrm{BA}$ cultured and incubated for $24 \mathrm{~h}$ at $37^{\circ} \mathrm{C}$. The colonies from BA culture were inoculated into $3 \mathrm{~mL}$ of phage broth for $2 \mathrm{~h}$ with vigorous shaking. The phage broth was then poured on phage agar plate with the removal of excess broth. After that bacteriophages were applied and left to dry in room temperature for an overnight incubation at $37^{\circ} \mathrm{C}$ the phage lysis pattern of each culture was then evaluated according to Ward et al. (1987) scheme. Resulted phage type was SEPT 1.

Inoculums preparation: SE colonies where cultured on nutrient agar for $24 \mathrm{~h}$ at $37^{\circ} \mathrm{C}$. The positive cultures were then cultured on BA for $24 \mathrm{~h}$ at $37^{\circ} \mathrm{C}$. The positive cultures were then harvested and placed in normal saline solution and then measured for the inoculums concentration by using the McFarland standard to prepare the inoculum in a concentration of $1 \times 10^{8}$ colony forming unit (cfu) per $\mathrm{mL}$.

Specific-pathogen-free chickens: Specific-Pathogen-Free (SPF) embryonated chicken eggs where obtained from the Veterinary Research Institute (VRI), Ipoh, Malaysia. The eggs where incubated (Black Chick, Siam Incubator System, Thailand) in Biologic Laboratory, Faculty of Veterinary Medicine, Universiti Putra Malaysia and upon hatching they were transferred into separate cages and granted free access to antibiotic-free ration and water supply. The cages where supported by artificial lighting and ventilation system.

Experimental design: About 21 day old chicks were divided into 3 groups namely SE, Control and Mortality groups. The chicks in SE and Mortality groups were orally inoculated with $0.1 \mathrm{~mL}$ of the SEPT 1 inoculum in a concentration of $1 \times 10^{8} \mathrm{cfu} \mathrm{mL}^{-1}$ while the Control group was not inoculated. About 3 chicks were humanly sacrificed by cervical dislocation prior to SE inoculation for bacteriological isolation and body weight measurement and from the SE and Control groups at every sampling dates at 6 and $12 \mathrm{~h}$ post inoculation (pi), 1, 2, 3, $5,7,10,14$ and 21 days (d) pi. Body weight was recorded from the chicks in SE and Control groups at the sampling dates. Clinical signs were observed at least twice daily throughout the trial. On necropsy gross lesions were observed. Samples of liver, spleen, blood, contents of the middle part of small intestine, caecum, caecal tonsils and cloacal swabs were collected in RV broth and incubated for $24 \mathrm{~h}$ at $37^{\circ} \mathrm{C}$ for $\mathrm{SE}$ isolation. Samples including liver, spleen, duodenum, jejunum, ileum and caecum were collected and fixed in $10 \%$ buffered formalin for histological examination. Caecal tonsils were also collected and fixed in $2.5 \%$ glutaraldehyde cacodylate buffer, $\mathrm{pH} 7.2$ at $4^{\circ} \mathrm{C}$ for ultrastructural examination using Scanning Electronic Microscopy (SEM). 
Bacterial isolation: Sample of liver, spleen, blood, contents of small intestine, caecum, caecal tonsils and cloacal sawbs where collected in RV broth at $37^{\circ} \mathrm{C}$ for $24 \mathrm{~h}$, then cultured on XLD agar and BG agar at $37^{\circ} \mathrm{C}$ for $24 \mathrm{~h}$. Positive colonies were then cultured on TSI and Urease biochemical tests. Positive colonies from the biochemical test were then identified serologically using the SAT (Van Der Zee, 1994).

Histopathology: Samples of liver, spleen, bursa of Fabricius, duodenum, jejunum, ileum and caecum were collected and fixed in $10 \%$ buffered formalin for $48 \mathrm{~h}$. Samples where processed and stained with Hematoxylin and Eosin (HE) (Bancroft et al., 1996). Briefly, the samples were trimmed into the required orientation and processed for dehydration in series of alcohol, cleaned with xylene using an automated tissue processor (Leica ASP 300, Germany). Samples were then embedded in paraffin (Leica EG 1160 , Germany), trimmed and sectioned at $4 \mu \mathrm{m}$ on microtome (Leica RM 2155, Germany). The paraffin sections where then mounted on glass slides (Leica $\mathrm{Hi}$ 1220). The slides were then stained using Hematoxylin and Eosin (HE) (Bancroft et al., 1996). Histopathological changes were recorded by examining the samples under $10,20,40$ and $100 \mathrm{x}$ objectives using the light microscope (Leica, Germany). For morphometric analysis, intestinal segments from duodenum, jejunum and ileum samples were examined under 10 and $20 \mathrm{x}$ objectives for the villus height and crypts depth measurement, respectively. Villus height was measured from the tip of the villi to the villus crypt junction, whilst crypt depth was measured from the base of the crypt to the crypt villi junction.

Scanning electron microscopy: Caecal tonsils samples were taken from chicks sacrificed at 6 and $12 \mathrm{~h}$, days 2,5 , 7 and 21 pi and fixed in $2.5 \%$ glutaraldehyde cacodylate buffer for $12 \mathrm{~h}$ and processed for viewing by the SEM (Watson et al., 1995). Briefly, samples where fixed in glutaraldehyde buffer for $12 \mathrm{~h}$ then washed with $0.1 \mathrm{M}$ sodium cacodylate buffer for 3 changes of $10 \mathrm{~min}$ each. Samples were then fixed with osmium terta-oxide for $2 \mathrm{~h}$ and washed with the $0.1 \mathrm{M}$ sodium cacodylate buffer for 3 changes of $10 \mathrm{~min}$ each. Then samples were dehydrated with series of acetone and run for the critical point drying, mounted on a double sided tape or colloidal silver. It was then coated with gold sputter or coater samples and viewed under SEM.

\section{RESULTS AND DISCUSSION}

Body weight: The body weight in the SE group increased continuously starting day 7 pi and thereafter. When compared to the Control, SE group was lower throughout
Table 1: The body weight of SPF chickens in the control and SE groups throughout the trial

\begin{tabular}{|c|c|c|}
\hline \multirow[b]{2}{*}{ Date (pi) } & \multicolumn{2}{|c|}{ Body weight (mean+SD, g)* } \\
\hline & Control & $\mathrm{SE}$ \\
\hline $0 \mathrm{~h}$ & $164 \pm 3^{\text {ac }}$ & $164 \pm 3^{\mathrm{ac}}$ \\
\hline $6 \mathrm{~h}$ & $205.5 \pm 8.2^{2, d}$ & $204.8 \pm 4.4^{\mathrm{a}, \mathrm{d}}$ \\
\hline $12 \mathrm{~h}$ & $214 \pm 7^{\mathrm{add}}$ & $196.1 \pm 24.2^{\mathrm{ad}}$ \\
\hline Day 1 & $228.8 \pm 31.3^{\mathrm{a}, \mathrm{d}}$ & $217.3 \pm 34^{\text {ad }}$ \\
\hline Day 2 & $231.3 \pm 4.7^{\mathrm{ad}}$ & $288.1 \pm 0.8^{\mathrm{a}, \mathrm{d}}$ \\
\hline Day 3 & $260.9 \pm 9.1^{1, e}$ & $262.6 \pm 40.1^{\text {ad }}$ \\
\hline Day 5 & $249.3 \pm 11.5^{\mathrm{a}, \mathrm{f}}$ & $281.8 \pm 10.7^{b, c}$ \\
\hline Day 7 & $332.2 \pm 15.9^{\mathrm{a}, \mathrm{g}}$ & $261.3 \pm 13.5^{b, e}$ \\
\hline Day 10 & $334.4 \pm 23.6^{\mathrm{a}, \mathrm{g}}$ & $303.4 \pm 7.3^{\mathrm{a}, \mathrm{f}}$ \\
\hline Day 14 & $469.3 \pm 52.9^{\mathrm{a}, \mathrm{h}}$ & $350.3 \pm 22.9^{b, 8}$ \\
\hline Day 21 & $501.6 \pm 27.5^{\mathrm{a}, \mathrm{h}}$ & $451 \pm 44.1^{\mathrm{a}, \mathrm{h}}$ \\
\hline
\end{tabular}

*The mean with $\mathrm{b}$ in the superscript in the SE group means it vary significantly with the other mean in the same row while the mean with different letter (c-h) in the superscript means it vary significantly with the previous mean within the same column; level of significance was accepted at $(\mathrm{p}<0.05)$

the trial, except at days $2,3,5$ pi, however the significant decreased $(\mathrm{p}<0.05)$ was only recorded at days 7 and 14 pi (Table 1).

Clinical signs: No abnormal clinical signs where observed in the Control group throughout the trial. However, diarrhoea was recorded in $100 \%$ of the examined chicks starting day 2 pi until day 7 pi. Inappetance was recorded starting day 3 pi and thereafter while ruffled feathers and stunting where recorded stating day 5 pi and thereafter. Diarrhoea was observed in the Mortality group $(100 \%)$ starting day $2 \mathrm{pi}$ and it lasted until day $10 \mathrm{pi}$. At day 3 pi and thereafter inappetance was observed. Ruffled feathers and stunting was observed starting day 5 pi and thereafter.

Gross lesions: No gross lesions where recorded in the Control group throughout the trial. However, in the SE group mild airsacculitis and mild peritonitis where recorded at days $2 \mathrm{pi}(66 \%), 3$ pi and 5 pi (100\%). Liver congestion was recorded at days 3 and 5 pi $(33 \%)$. No gross lesions where recorded thereafter (Fig. 1).

Bacteriological isolation: No SE was isolated in the Control group throughout the trial. In the SE group, SE was isolated from liver only at day $3 \mathrm{pi}(33 \%)$; from spleen at days 1 and 3 pi (33\%); from blood samples at day 3 pi (33\%); from contents of small intestine at day 3 pi $(33 \%)$; from caecum contents at $12 \mathrm{~h}$ pi $(66 \%)$, day 1 and 3 pi $(33 \%)$ and day $2 \mathrm{pi}(100 \%)$; from caecal tonsils at day $2 \mathrm{pi}$ $(66 \%)$; no SE was isolated from cloacal swabs throughout the trial.

\section{Villi length}

Duodenum: The villi height in the SE group was fluctuating throughout the trail. When compared to the Control group the villi height in the SE group was lower 

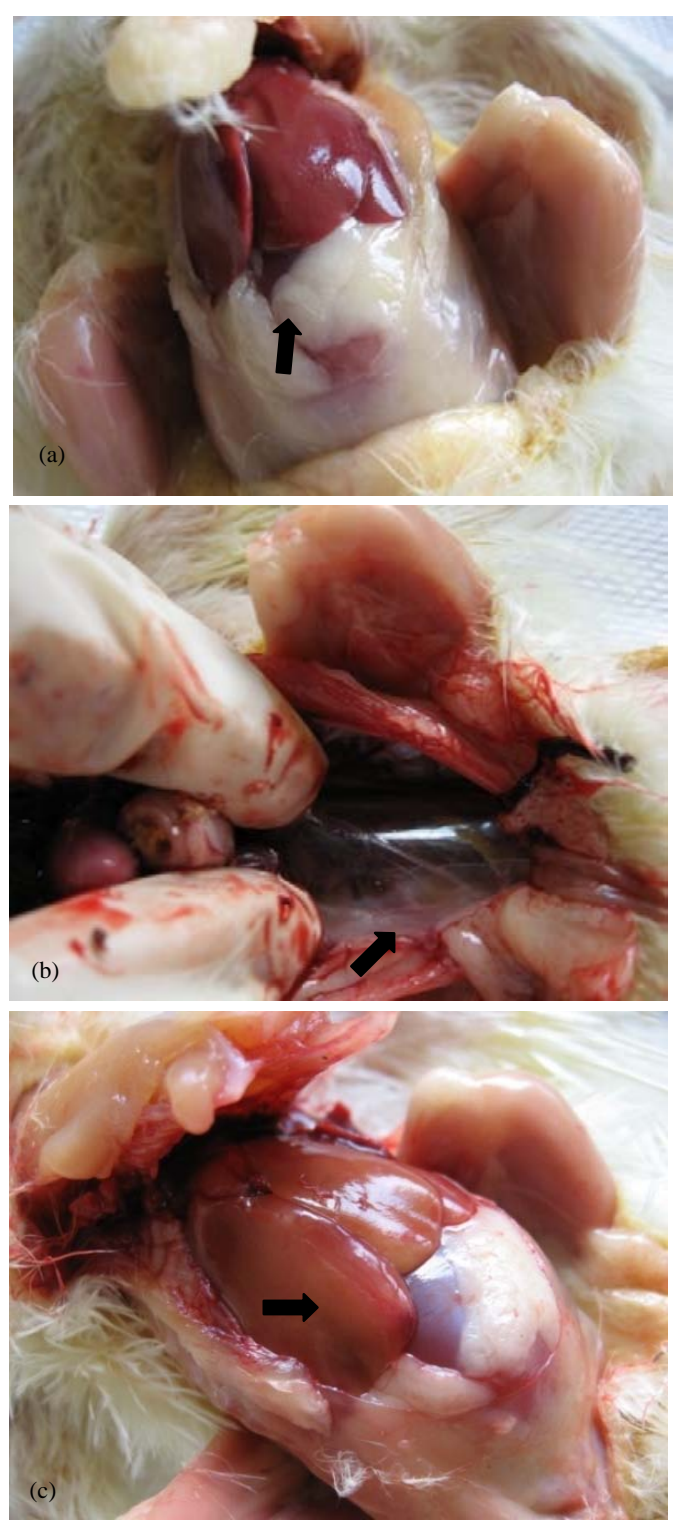

Fig. 1: The gross lesions of SPF chickens in the SE group. (a) Mild peritonitis; (b) Mild airsacculitis at day 5 pi and (c) Mild hepati ccongestion at day 5 pi

throughout the trial however, significant decreased $(\mathrm{p}<0.05)$ was recorded at $12 \mathrm{~h}$, days $1,3,5,10,14$ and $21 \mathrm{pi}$ (Table 2).

Jejunum: The villi height measurement in the SE group was fluctuating, however it increased continuously starting day 14 pi and thereafter. When compared to the Control group the SE group villi height measured lower throughout the trial except at day 1 pi however, the decreased was significant $(\mathrm{p}<0.05)$ at $6 \mathrm{~h}$, days 2,14 and 21 pi (Table 3).
Table 2: The duodenal villus height of SPF chickens in the control and SE groups throughout the trial

\begin{tabular}{lcr}
\hline & Villus height (mean+SD, $\mu \mathrm{m})^{*}$ \\
& \multicolumn{3}{c}{ Control } & \multicolumn{1}{c}{ SE } \\
\hline Date (pi) & $1160 \pm 87^{\mathrm{a}, \mathrm{c}}$ & $1160 \pm 87^{\mathrm{a}, \mathrm{c}}$ \\
$0 \mathrm{~h}$ & $1349 \pm 198^{\mathrm{a}, \mathrm{c}}$ & $1082 \pm 155^{\mathrm{a}, \mathrm{c}}$ \\
$6 \mathrm{~h}$ & $1197 \pm 82^{\mathrm{a}, \mathrm{c}}$ & $1000 \pm 47^{\mathrm{b}, \mathrm{c}}$ \\
$12 \mathrm{~h}$ & $1401 \pm 16^{\mathrm{a}, \mathrm{d}}$ & $899 \pm 146^{\mathrm{b}, \mathrm{c}}$ \\
Day 1 & $1246 \pm 171^{\mathrm{a}, \mathrm{d}}$ & $974 \pm 172^{\mathrm{a}, \mathrm{c}}$ \\
Day 2 & $1168 \pm 194^{\mathrm{a}, \mathrm{d}}$ & $771 \pm 169^{\mathrm{b}, \mathrm{c}}$ \\
Day 3 & $1299 \pm 27^{\mathrm{a}, \mathrm{d}}$ & $934 \pm 85^{\mathrm{b}, \mathrm{c}}$ \\
Day 5 & $1274 \pm 165^{\mathrm{a}, \mathrm{d}}$ & $1175 \pm 82^{\mathrm{a}, \mathrm{d}}$ \\
Day 7 & $1587 \pm 48^{\mathrm{a}, \mathrm{e}}$ & $1279 \pm 42^{\mathrm{b}, \mathrm{d}}$ \\
Day 10 & $1733 \pm 72^{\mathrm{a}, \mathrm{f}}$ & $1230 \pm 62^{\mathrm{b}, \mathrm{d}}$ \\
Day 14 & $1885 \pm 55^{\mathrm{a}, \mathrm{d}}$ & $1200 \pm 22^{\mathrm{b}, \mathrm{d}}$ \\
Day 21 &
\end{tabular}

*The mean with $\mathrm{b}$ in the superscript in the SE group means it vary significantly with the other mean in the same row while the mean with different letter (c-g) in the superscript means it vary significantly with the previous mean within the same column; level of significance was accepted at $(\mathrm{p}<0.05)$

Table 3: The jejunal villus height of SPF chickens in the control and SE groups throughout the trial

\begin{tabular}{|c|c|c|}
\hline \multirow[b]{2}{*}{ Date (pi) } & \multicolumn{2}{|c|}{ Villus height $(\text { mean }+\mathrm{SD}, \mu \mathrm{m})^{*}$} \\
\hline & Control & $\mathrm{SE}$ \\
\hline $0 \mathrm{~h}$ & $577 \pm 97^{a, c}$ & $577 \pm 97^{\mathrm{ac}}$ \\
\hline $6 \mathrm{~h}$ & $798 \pm 63^{\text {ad }}$ & $645 \pm 70^{b, c}$ \\
\hline $12 \mathrm{~h}$ & $806 \pm 95^{\text {ad }}$ & $705 \pm 72^{\mathrm{ac}}$ \\
\hline Day 1 & $730 \pm 42^{\text {ad }}$ & $786 \pm 35^{\mathrm{a}, \mathrm{c}}$ \\
\hline Day 2 & $874 \pm 56^{\text {a,e }}$ & $661 \pm 78^{b, d}$ \\
\hline Day 3 & $842 \pm 110^{\text {ae }}$ & $697 \pm 69^{9, d}$ \\
\hline Day 5 & $1012 \pm 191^{\text {se }}$ & $820 \pm 8^{\text {se }}$ \\
\hline Day 7 & $1077 \pm 54^{\text {a }}$ & $1040 \pm 51^{\text {a,f }}$ \\
\hline Day 10 & $1116 \pm 126^{\text {aee }}$ & $1017 \pm 76^{\mathrm{aff}}$ \\
\hline Day 14 & $1207 \pm 59^{\mathrm{a} e}$ & $911 \pm 74^{\mathrm{b}, \mathrm{f}}$ \\
\hline Day 21 & $1263 \pm 8^{\text {ae }}$ & $1165 \pm 78^{\mathrm{b}, \mathrm{g}}$ \\
\hline
\end{tabular}

*The mean with $b$ in the superscript in the SE group means it vary significantly with the other mean in the same row while the mean with different letter (c-g) in the superscript means it vary significantly with the previous mean within the same column; level of significance was accepted at $(\mathrm{p}<0.05)$

Ileum: The villi height in the SE group was fluctuating however, it continuously increased starting day 10 pi and thereafter. When compared to the Control group the villi height in the SE measured lower than the Controls starting $12 \mathrm{~h}$ pi and thereafter except at days 7 and 10 pi however, significant decreased $(\mathrm{p}<0.05)$ was recorded at days 1,3 and 5 pi (Table 4).

\section{Crypts depth}

Duodenum: The crypts depth measurement in the SE group was fluctuating, however it increased continuously starting day 7 pi and thereafter. The crypts depth in the SE group was lower throughout the trial when compared to the Control group, except days 5 and 21 pi, however it was significantly lower $(\mathrm{p}<0.0 .5)$ at $6 \mathrm{~h}$ and day $14 \mathrm{pi}$ (Table 5).

Jejunum: The crypts depth measurement in the SE group was fluctuating throughout the trial. The SE group crypts depth was lower when compared to the Controls at 6 and $12 \mathrm{~h}$, days 1,2 and 10 pi however, it was significantly lower $(\mathrm{p}<0.05)$ at day 10 pi only (Table 6$)$. 
Table 4: The ileum villus height of SPF chickens in the control and SE groups throughout the trial

\begin{tabular}{|c|c|c|}
\hline \multirow[b]{2}{*}{ Date (pi) } & \multicolumn{2}{|c|}{ Villus height $(\text { mean }+\mathrm{SD}, \mu \mathrm{m})^{*}$} \\
\hline & Control & SE \\
\hline $0 \mathrm{~h}$ & $537 \pm 39^{a, c}$ & $537 \pm 39^{a, c}$ \\
\hline $6 \mathrm{~h}$ & $604 \pm 22^{\text {a,d }}$ & $645 \pm 74^{\text {a d }}$ \\
\hline $12 \mathrm{~h}$ & $703 \pm 83^{\text {ad }}$ & $670 \pm 51^{\text {a,d }}$ \\
\hline Day 1 & $633 \pm 5^{\mathrm{a}, \mathrm{d}}$ & $565 \pm 52^{b, e}$ \\
\hline Day 2 & $704 \pm 241^{\text {a,d }}$ & $653 \pm 111^{\mathrm{a}, \mathrm{e}}$ \\
\hline Day 3 & $720 \pm 41^{\text {a,d }}$ & $594 \pm 26^{\text {b,e }}$ \\
\hline Day 5 & $753 \pm 30^{\text {ad }}$ & $604 \pm 32^{b, e}$ \\
\hline Day 7 & $797 \pm 65^{\text {add }}$ & $882 \pm 98^{\mathrm{a}, \mathrm{f}}$ \\
\hline Day 10 & $866 \pm 108^{\mathrm{a}, \mathrm{d}}$ & $873 \pm 126^{\mathrm{af}}$ \\
\hline Day 14 & $1112 \pm 49^{\text {ae }}$ & $1052 \pm 45^{\text {ag }}$ \\
\hline Day 21 & $1108 \pm 47^{\text {a }}$ & $1063 \pm 73^{\text {ag }}$ \\
\hline
\end{tabular}

*The mean with $\mathrm{b}$ in the superscript in the SE group means it vary significantly with the other mean in the same row while the mean with different letter $(c-g)$ in the superscript means it vary significantly with the previous mean within the same column; level of significance was accepted at $(\mathrm{p}<0.05)$

Table 5: The duodenum crypts depth of SPF chickens in the control and SE groups throughout the trial

\begin{tabular}{lcr} 
& \multicolumn{3}{c}{ Crypts depth (mean+SD, $\mu \mathrm{m})^{*}$} \\
& Control & $\mathrm{SE}$ \\
\hline Date (pi) & $68 \pm 10^{\mathrm{a}, \mathrm{c}}$ & $68 \pm 10^{\mathrm{a}, \mathrm{c}}$ \\
$0 \mathrm{~h}$ & $70 \pm 9^{\mathrm{a}, \mathrm{c}}$ & $58 \pm 2^{\mathrm{b}, \mathrm{c}}$ \\
$6 \mathrm{~h}$ & $61 \pm 14^{\mathrm{a}, \mathrm{c}}$ & $56 \pm 2^{\mathrm{a}, \mathrm{c}}$ \\
$12 \mathrm{~h}$ & $70 \pm 12^{\mathrm{a}, \mathrm{c}}$ & $65 \pm 1^{\mathrm{a}, \mathrm{d}}$ \\
Day 1 & $67 \pm 2^{\mathrm{a}, \mathrm{c}}$ & $63 \pm 8^{\mathrm{a}, \mathrm{d}}$ \\
Day 2 & $67 \pm 4^{\mathrm{a}, \mathrm{c}}$ & $57 \pm 6^{\mathrm{a}, \mathrm{d}}$ \\
Day 3 & $60 \pm 11^{\mathrm{a}, \mathrm{c}}$ & $68 \pm 8^{\mathrm{a}, \mathrm{d}}$ \\
Day 5 & $68 \pm 2^{\mathrm{a}, \mathrm{c}}$ & $62 \pm 4^{\mathrm{a}, \mathrm{d}}$ \\
Day 7 & $98 \pm 27^{\mathrm{a}, \mathrm{c}}$ & $71 \pm 5^{\mathrm{a}, \mathrm{e}}$ \\
Day 10 & $86 \pm 5^{\mathrm{a}, \mathrm{c}}$ & $75 \pm 4^{\mathrm{b}, \mathrm{e}}$ \\
Day 14 & $83 \pm 7^{\mathrm{a}, \mathrm{c}}$ & $84 \pm 4^{\mathrm{a}, \mathrm{f}}$ \\
Day 21 & The mean with b in the superscript in the SE group means it vary \\
significantly with the other mean in the same row while the mean with \\
different letter (c-f) in the superscript means it vary significantly with the \\
previous mean within the same column; level of significance was accepted \\
at (p<0.05)
\end{tabular}

Table 6: The jejunal crypts depth of SPF chickens in the control and SE groups throughout the trial

\begin{tabular}{lcr}
\hline & Crypts depth (mean+SD, $\mu \mathrm{m})^{*}$ \\
\hline Date (pi) & Control & $\mathrm{SE}$ \\
\hline $0 \mathrm{~h}$ & $60 \pm 5^{\mathrm{a}, \mathrm{c}}$ & $60 \pm 5^{\mathrm{a}, \mathrm{c}}$ \\
$6 \mathrm{~h}$ & $61 \pm 5^{\mathrm{a}, \mathrm{c}}$ & $63 \pm 3^{\mathrm{a}, \mathrm{c}}$ \\
$12 \mathrm{~h}$ & $55 \pm 8^{\mathrm{a}, \mathrm{c}}$ & $58 \pm 1^{\mathrm{a}, \mathrm{d}}$ \\
Day 1 & $59 \pm 4^{\mathrm{a}, \mathrm{c}}$ & $58 \pm 6^{\mathrm{a}, \mathrm{d}}$ \\
Day 2 & $62 \pm 6^{\mathrm{a}, \mathrm{c}}$ & $61 \pm 9^{\mathrm{a}, \mathrm{d}}$ \\
Day 3 & $59 \pm 8^{\mathrm{a}, \mathrm{c}}$ & $62 \pm 3^{\mathrm{a}, \mathrm{d}}$ \\
Day 5 & $50 \pm 3^{\mathrm{a}, \mathrm{c}}$ & $64 \pm 4^{\mathrm{b}, \mathrm{d}}$ \\
Day 7 & $68 \pm 4^{\mathrm{a}, \mathrm{d}}$ & $75 \pm 5^{\mathrm{a}, \mathrm{e}}$ \\
Day 10 & $86 \pm 4^{\mathrm{a}, \mathrm{e}}$ & $67 \pm 6^{\mathrm{b}, \mathrm{f}}$ \\
Day 14 & $72 \pm 4^{\mathrm{a}, \mathrm{f}}$ & $77 \pm 8^{\mathrm{a}, \mathrm{f}}$ \\
Day 21 & $72 \pm 3^{\mathrm{a}, \mathrm{f}}$ & $76 \pm 4^{\mathrm{a}, \mathrm{f}}$ \\
*The mean with b in the superscript in the SE group means it vary \\
significantly with the other mean in the same row while the mean with \\
different letter (c-f) in the superscript means it vary significantly with the \\
previous mean within the same column; level of significance was accepted \\
at (p<0.05)
\end{tabular}

Ileum: Crypts depth in the SE groups was fluctuating as well throughout the trial. The crypts depth in the SE group was lower when compared to the Control group at 6 and $12 \mathrm{~h}$, days 1,2 and 10 pi however, significance $(\mathrm{p}<0.05$ ) was detected at $12 \mathrm{~h}$ pi only (Table 7 ).
Table 7: The ileum crypts depth of SPF chickens in the control and SE groups throughout the trial

\begin{tabular}{|c|c|c|}
\hline \multirow[b]{2}{*}{ Date (pi) } & \multicolumn{2}{|c|}{ Crypts depth $(\text { mean+SD, } \mu \mathrm{m})^{*}$} \\
\hline & Control & $\mathrm{SE}$ \\
\hline $0 \mathrm{~h}$ & $51 \pm 3^{\text {ac }}$ & $51 \pm 3^{\text {ac }}$ \\
\hline $6 \mathrm{~h}$ & $57 \pm 2^{\mathrm{a}, \mathrm{d}}$ & $55 \pm 2^{\mathrm{a}, \mathrm{c}}$ \\
\hline $12 \mathrm{~h}$ & $60 \pm 1^{\text {a,d }}$ & $48 \pm 2^{b, c}$ \\
\hline Day 1 & $52 \pm 2^{\mathrm{aee}}$ & $51 \pm 1^{\text {sc }}$ \\
\hline Day 2 & $59 \pm 5^{\mathrm{a}} \mathrm{f}$ & $56 \pm 1^{4,9}$ \\
\hline Day 3 & $54 \pm 6^{\mathrm{aff}}$ & $59 \pm 5^{\mathrm{a}, \mathrm{e}}$ \\
\hline Day 5 & $53 \pm 6^{\mathrm{aff}}$ & $55 \pm 7^{\mathrm{a}, \mathrm{c}}$ \\
\hline Day 7 & $63 \pm 5^{\mathrm{a}, g}$ & $64 \pm 6^{\mathrm{a}, \mathrm{e}}$ \\
\hline Day 10 & $71 \pm 3^{\mathrm{a}, 8}$ & $62 \pm 7^{4,9}$ \\
\hline Day 14 & $74 \pm 3^{2,8}$ & $75 \pm 2^{\mathrm{a}, \mathrm{e}}$ \\
\hline Day 21 & $70 \pm 9^{9} 8$ & $75 \pm 4^{2,1}$ \\
\hline
\end{tabular}

*The mean with $\mathrm{b}$ in the superscript in the SE group means it vary significantly with the other mean in the same row while the mean with different letter $(\mathrm{c}-\mathrm{g})$ in the superscript means it vary significantly with the previous mean within the same column; level of significance was accepted at $(\mathrm{p}<0.05)$

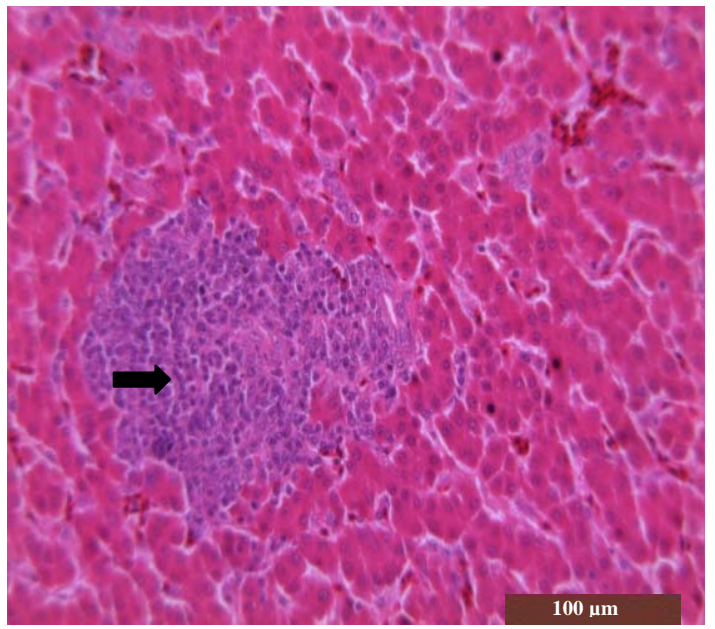

Fig. 2: The histopathological changes in the liver of SPF chickens in the SE group. Hepatitis and areas of necrosis at day 5 pi. $\mathrm{HE}, \mathrm{Bar}=100 \mu \mathrm{m}$

Histopathological changes: No histopathological changes were detected in the Control group throughout the trial. However, mild hepatitis was recorded in the SE group starting $6 \mathrm{~h}$ pi until day 1 pi while moderate hepatitis and congestion where recorded starting day 2 pi until day 5 pi. Mild hepatitis, congestion and areas of focal necrosis were observed starting day 5 pi and thereafter (Fig. 2). Mild splenitis was recorded in the SE group starting $6 \mathrm{~h}$ pi until day 1 pi. Mild splenitis and congestion was recorded starting day 2 pi and thereafter. Areas of hyperplastic islands, increased hetrophilic infiltration and oedema surrounding the adenoid sheathed arteries were observed at day 7 pi and thereafter (Fig. 3). Mild inflammation of the bursa of Fabricius was recorded in the SE group starting $6 \mathrm{~h}$ pi until day 2 pi. Mild inflammation, congestion, degeneration and necrosis in the lymphoid follicles were observed starting day 3 pi and thereafter (Fig. 4). Mild 


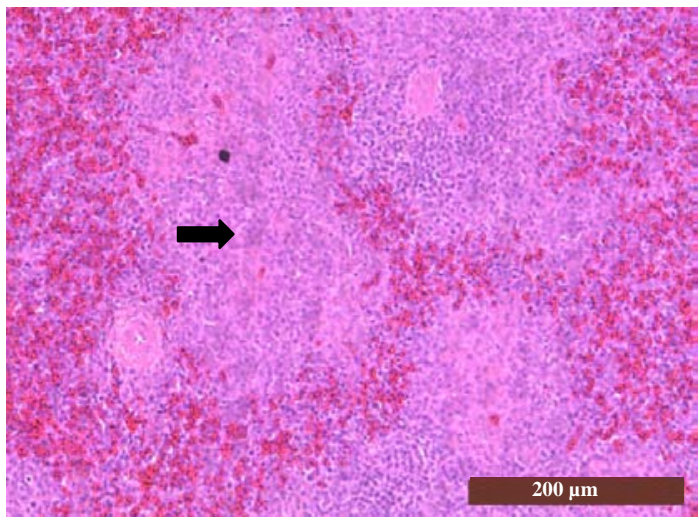

Fig. 3: The histopathological changes in the spleen of SPF chickens in the SE group. Congestion, increased cellularity and hyperplastic cells at day 7 pi. $\mathrm{HE}, \mathrm{Bar}=200 \mu \mathrm{m}$

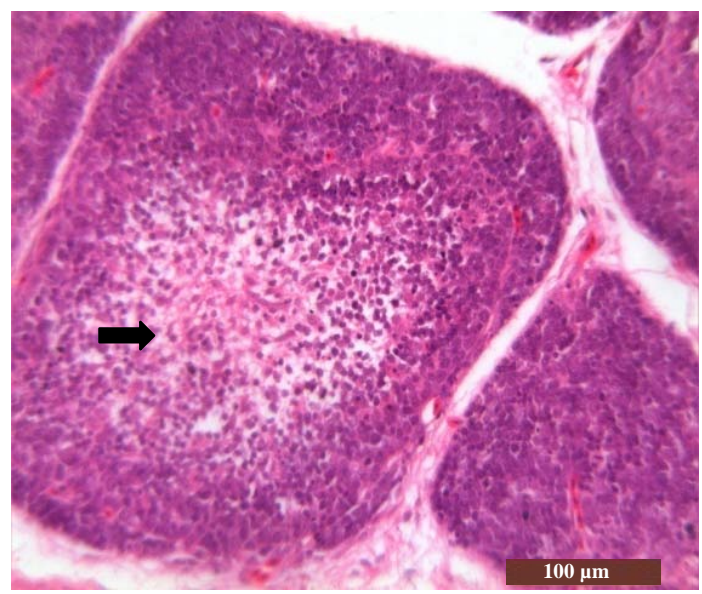

Fig. 4: The histopathological changes in the bursa of Fabricius of SPF chickens in the SE group. Degeneration and necrosis of lymphoid cells at day 2 pi. $\mathrm{HE}, \mathrm{Bar}=100 \mu \mathrm{m}$

enteritis was observed in duodenum, jejunum, ileum and caecum in the SE group at 6 and $12 \mathrm{~h}$ pi. Mild enteritis, congestion and sloughing of the necrotised enterocytes into the villi lumen was recorded in the intestine and bacterial clusters where seen passing to the intestinal villi through sloughed epithelium stating day 5 and thereafter (Fig. 5-8).

Scanning electron microscopy: SE found to be present in the caecal tonsils interepithelial junctions and were seen to be engulfed by macrophages in the SE group at day 1 pi (Fig. 9). At day 2 pi, engulfment of the SE by the macrophages and necrosis of the enterocytes in the

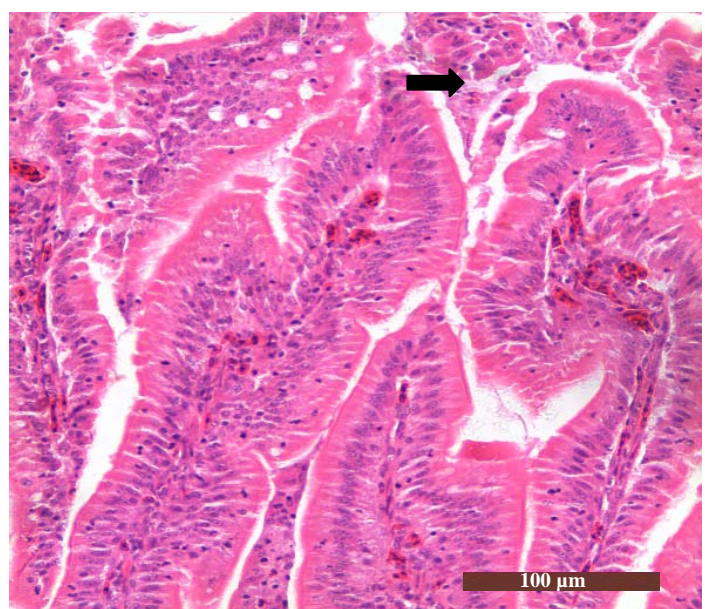

Fig. 5: The histopathological changes in the duodenum of SPF chickens in the SE group. Congestion of the duodenal villi and sloughing of the necrotic enterocytes with bacterial custers in the intestinal lumen. $\mathrm{HE}, \mathrm{Bar}=100 \mu \mathrm{m}$

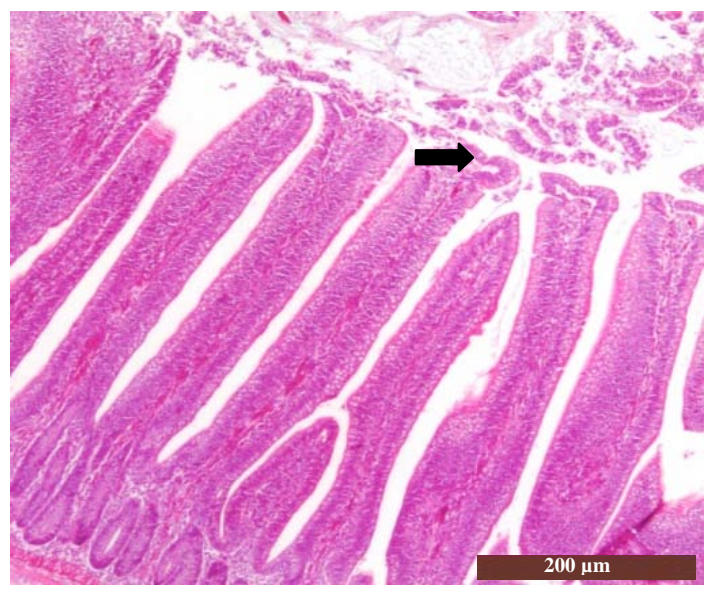

Fig. 6: The histopathological changes in the jejunum of SPF chickens in the SE group. Sloughing of the necrotic enterocytes into the intestinal lumen at day 7 pi. $\mathrm{HE}, \mathrm{Bar}=200 \mu \mathrm{m}$

caecal tonsils villi surface was recorded with infiltration of the bacteria through these areas (Fig. 10). At day 5 pi, bacterial multiplication where seen and often they were located by the M-like $M$ cells however no actual engulfment was recorded.

The paratyphoid infection normally cause a subclinical infection in adult chickens infected after 2 weeks of hatching (Girard-Santosuosso et al., 1998), however few experimental studies showed the susceptibility of chickens to be infected using 


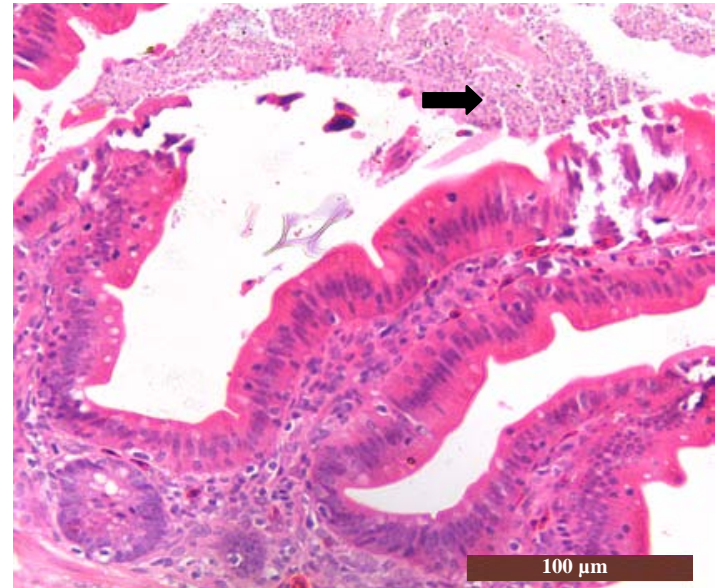

Fig. 7: The histopathological changes in the ileum of SPF chickens in the SE group. Necrosis of the enterocytes and bacterial clusters in the intestinal lumen at day $10 \mathrm{pi}$. $\mathrm{HE}, \mathrm{Bar}=100 \mu \mathrm{m}$

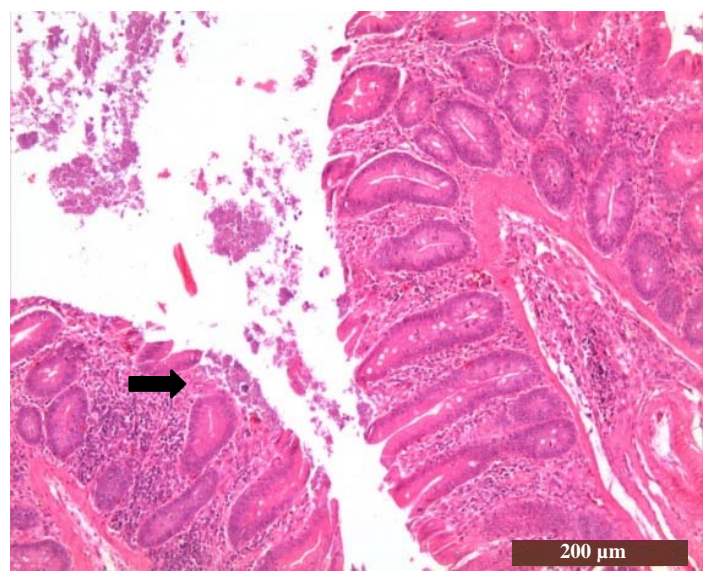

Fig. 8: The histopathological changes in the caecum of SPF chickens in the SE group. Necrosis of the enterocytes and bacterial clusters infiltration into the intestinal villi at day 7 pi. $\mathrm{HE}, \mathrm{Bar}=200 \mu \mathrm{m}$

pathogenic phage types and high inoculums concentration (Holt, 1993). The infection of adult chickens defiantly raise the alarm for environmental contamination and elevate the risk of food poisoning outbreaks caused by consumption of poultry or poultry products polluted by the these pathogens (Dhillon et al., 1999). In the present study the oral inoculation of 21 day old SPF chickens resulted in mild pathogenic infection. However, the body weight in the $\mathrm{SE}$ group was lower throughout the trial except for days 2,3 and 5 pi reaching its peak at day 14 pi when SE measured $26 \%$ lower than the controls.

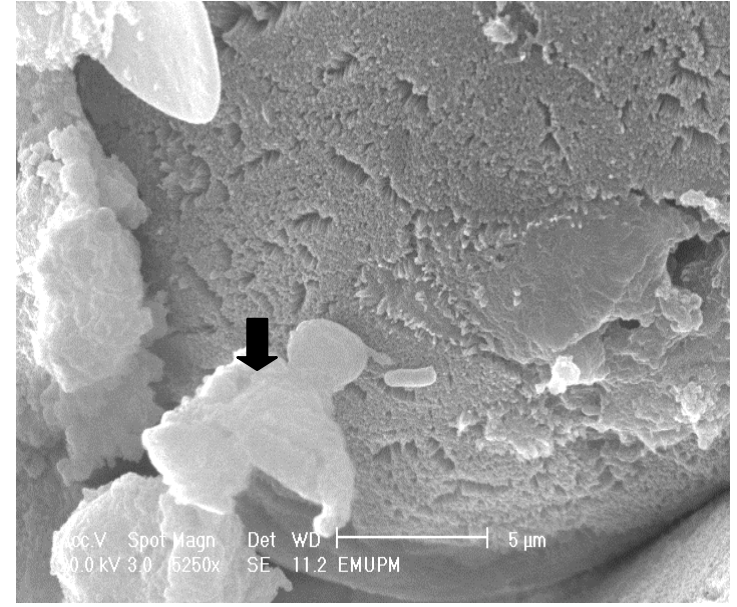

Fig. 9: The ultrastructural changes in the caecal tonsil of SPF chickens in the SE group. Bacterial engulfment by the macrophages at day 1 pi. SEM, $\mathrm{Bar}=5 \mu \mathrm{m}$

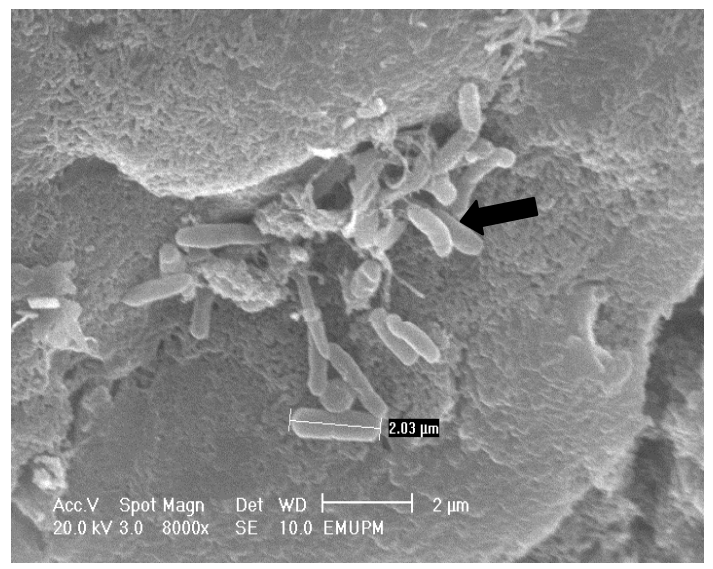

Fig. 10: The ultrastructural changes in the caecal tonsils of SPF chickens in the SE group. Bacterial infiltration through the enterocyte at day 2 pi. $\mathrm{SEM}, \mathrm{Bar}=2 \mu \mathrm{m}$

Clinical signs observed in the infected chickens included diarrhoea, inappetance, ruffled feathers and stunting of the chickens in the period starting day $2 \mathrm{pi}$ and thereafter while no abnormal clinical signs were seen in the Control group. Although, the profuse watery diarrhea started at day 2 pi in all the chickens examined and lasted until day 7 pi in the SE group however the effect on weight loss didn't show up until day 7 pi while earlier studies showed a significant change in body weight throughout the trial in adult infected chickens (Eigaard et al., 2006). The gross lesions observed between day 2 pi to day 5 pi included mild airsacculitis, mild peritonitis and liver congestion. 
The intensity of clinical and gross findings coordinated with bacteriological isolation when $33 \%$ of liver, spleen, blood, jejunum and caecum where positive for $\mathrm{SE}$ at day 3 pi. Nevertheless the first isolation recorded was from the caecum at $12 \mathrm{~h}$ pi. The caecum was the most consistent site for SE isolation, SE was isolated from $66 \%$ at $12 \mathrm{~h} \mathrm{pi;} 33 \%$ at days 1 and $3 ; 100 \%$ at day 2 pi. First isolation of the SE from visceral organs was recorded in the spleen at day 1 pi $(33 \%)$ which marks the primary bactaeremia while day 3 pi might be the secondary bactaeremia mark as the pathogen can be isolated in bigger percentage from different sites in the chicken's body. This delay might indicate the enhancement of immune response of the adult chickens. However, interestingly observed but poorly understood no SE was isolated from the cloacal swabs throughout the trial, this might be related to the low concentration the organism was shed in which might cause the failure of the conventional methods to detect its presence. Nevertheless previous study recorded the persistence of $\mathrm{SE}$ in infected chickens for long periods after inoculation (Reiber et al., 1995; Shivaprasad et al., 1990).

The ration absorption is majorly occurs in the intestinal segment of the Gastrointestinal Tract (GIT) and the morphology of the villi and crypts depth will be a major factor in evaluating the eventual ration conversion rate and the ultimate chickens body weight (Uni et al., 1999). The intestinal villi in duodenum, jejunum and ileum where generally affected in the SE group and where lower when compared to the control. Crypts depth where affected as well however, the impact was lower than the one the villi had. Nevertheless, the crypts depth ended up by being higher in the SE group in the end of the trial at day $21 \mathrm{pi}$ in the jejunum and ileum. This lower impact in the intestinal crypt might refer to the presence of the segmented filamentous bacteria which an autochthonous bacterium is colonizing the ileum of many young animals by attachment to intestinal epithelial cells. These non pathogenic bacteria strongly stimulate the mucosal immune system by elevating immunoglobulin A-secreting cells (Klaasen et al., 1993) and have a possible protective role against SE infection (Garland et al., 1982).

Heterophilic infiltration in the liver, spleen, bursa of Fabricius, duodenum, jejunum, ileum and caecum indicated the inflammatory response of the infected tissues to the SE presence. However, progressive development of the histological changes in liver represented by focal necrosis, in spleen by hyperplastic islands and oedema of the adenoid lymphatic sheathed arteries, in the bursa by the areas of necrosis in the lymphoid follicles and in the intestine by the necrosis and sloughing of the enterocytes and infiltration of the bacteria indicated the continuous pathogenic effect of the bacteria and presence inside the body although no positive isolation was detected further than day 3 pi.

This was further demonstrated by detecting the bacteria under the SEM at day 5 pi in the caecal tonsils where multiplication of the bacteria where seen, however at earlier times at days 1 and 2 pi the intake of the organism was seen to take place by the engulfment of the bacteria by the macrophages and the infiltration of the bacteria through sloughed enterocytes on the villi surface in the caecal tonsils at day 2 pi. This might suggest that after day 2 pi the bacterial concentration in the caecal tonsils was lower than day 1 and 2 pi either by engulfment or penetration of the bacteria into the lamina propria, nevertheless a potential increase might occur in the stressed or immune suppressed chicks.

\section{CONCLUSION}

It was concluded that the SE PT 1 isolates of Malaysia is mild pathogenic to 21 day old SPF chickens. SE can successfully cause significant weight loss $(p<0.05)$ and systemic infection represented by bacterial isolation from visceral organs and the impact caused grossly and histologically on the examined organs which might be exaggerated in stressed or immune suppressed chickens. Although, the organism was not detected by the conventional methods used for isolation, however its presence was detected by the SEM examination and histopathological changes caused which strongly suggest the improvement of screening methods applied for $\mathrm{SE}$ detection.

\section{ACKNOWLEDGEMENT}

This research was funded by FRGS grant 5523308 from the Ministry of High Education, Malaysia.

\section{REFERENCES}

Bancroft, J.D., A. Stevens and D.R. Turner, 1996. Theory and Practice of Histological Techniques. 4th Edn., Churchill Livingstone, London.

Barrow, P.A. and M.A. Lovell, 1991. Experimental infection of egg-laying hens with Salmonella enteritidis phage type 4. Avian Pathol., 20: 335-348.

Davies, R.H., R.A.J. Nicholas, I.M. McLaren, J.D. Corkish, D.G. Lanning and C. Wray, 1997. Bacteriological and serological investigation of persistent Salmonella enteritidis infection in an integrated poultry organisation. Vet. Microbiol., 58: 277-293. 
Desmidt, M., R. Ducatelle and F. Haesebrouck, 1997. Pathogenesis of Salmonella enteritidis phage type four after experimental infection of young chickens. Vet. Microbiol., 56: 99-109.

Dhillon, A.S., B. Alisantosa, H.L. Shivaprasad, O. Jack, D. Schaberg and D. Bandli, 1999. Pathogenicity of Salmonella enteritidis phage types 4,8 and 23 in broiler chicks. Avian Dis., 73: 506-515.

Eigaard, N.M., T.W. Schou, A. Permin, J.P. Christensen and C.T. Ekstrm et al., 2006. Infection and excretion of Salmonella enteritidis in two different chicken lines with concurrent Ascaridia galli infection. Avian Path., 35: 487-493.

Garland, C.D., A. Lee and M.R. Dickson, 1982. Segmented filamentous bacteria in the rodent small intestine: Their colonization of growing animals and possible role in host resistance to Salmonella. Microbiol. Ecol., 8: 181-190.

Gast, R.K. and C.W. Beard, 1990. Isolation of Salmonella enteritidis from internal organs of experimentally infected hens. Avian Dis., 34: 991-993.

Girard-Santosuosso, O., P. Menanteau, M. DuchetSuchaux, F. Berthelot and F. Mompart et al., 1998. Variability in the resistance of four chicken lines to experimental intravenous infection with Salmonella entritidis phage type 4. Avian Dis., 42: 462-496.

Holt, P.S., 1993. Effect of induced molting on the susceptibility of white leghorn hens to a Salmonella enteritidis infection. Avian Dis., 37: 412-417.

Kinde, H., H.L. Shivaprasad, B.M. Daft, D.H. Read and A. Ardans et al., 2000. Pathologic and bacteriologic findings in 27-week-old commercial laying hens experimentally infected with Salmonella enteritidis, phage type 4. Avian Dis., 44: 239-248.

Klaasen, H.L.B.M., P.J. van der Heijden, W. Stok, F.J.G. Poelma and J.P. Koopman et al., 1993. Apathogenic, intestinal, segmented, filamentous bacteria stimulate the mucosal immune system of mice. Infect. Immun., 61: 303-306.
Le Bacq, F., B. Louwagie and J. Verhaegen, 1994. Salmonella typhimurium and Salmonella enteritidis: Changing epidemiology from 1973 until 1992. Eur. J. Epidemiol., 10: 367-371.

Reiber, M.A., D.E. Conner and S.F. Bilgili, 1995. Salmonella colonization and shedding patterns of hens inoculated via semen. Avian Dis., 39: 317-322.

Saif, Y.M., 2003. Paratyphoid Infections. In: Diseases of Poultry, Calnek, B.W., H.J. Barnes and C.W. Beard (Eds.). 11th Edn., Iowa State University Press, USA.

Sakai, T. and T. Chalermchaikit, 1996. The major sources of Salmonella enteritidis in Thailand. Int. J. Food Microbiol., 31: 173-180.

Shivaprasad, H.L., J.F. Timoney, S. Morales, B. Lucio and R.C. Baker, 1990. Pathogenesis of Salmonella enteritidis infection in laying chickens. I. Studies on egg transmission, clinical signs, fecal shedding and serologic responses. Avian Dis., 34: 548-557.

Soliman, E.S., E. Taha, K.D. Infante, K. Laboy, M.A. Sobieh and P.G. Reddy, 2009. Stressors influence on Salmonella enterica serovar Enteritidis colonization in broilers. Am. J. Anim. Vet. Sci., 4: 42-48.

Uni, Z., Y. Noy and D. Sklan, 1999. Posthatch development of small intestinal function in the poult. Poult. Sci., 78: 215-222.

Van Der Zee, H., 1994. Conventional methods for the detection and isolation of Salmonella enteritidis. Int. J. Food Microbiol., 21: 41-46.

Ward, L.R., J.D.H. De-Sa and B. Rowe, 1987. A phagetyping scheme for Salmonella enteritidis. Epidemiol. Infect., 99: 291-294.

Watson, P.R., S.M. Paulin, A.P. Bland, P.W. Jones and T.S. Wallis, 1995. Characterization of intestinal invasion by Salmonella typhimurium and Salmonella dublin and effect of a mutation in the invH gene. Infect. Immun., 63: 2743-2757. 